\title{
Cartesian dualism and the study of cultural artefacts
}

\section{Terence Rajivan Edward ${ }^{1}$}

Abstrakt: This paper evaluates an argument according to which many anthropologists commit themselves to Cartesian dualism, when they talk about meanings. This kind of dualism, it is argued, makes it impossible for anthropologists to adequately attend to material artefacts. The argument is very original, but it is also vulnerable to a range objections.

Keywords: Cartesian dualism, cultural artefacts.

1 The University of Manchester, School of Social Sciences, Arthur Lewis Building, The University of Manchester, Manchester. M13 9PL, United Kingdom, t.r.edward@manchester.ac.uk 


\section{Introduction}

In their studies of cultural diversity, social anthropologists perceive and acquire information about material artefacts. For example, an anthropologist doing fieldwork may hear, see and touch types of musical instrument which they have never heard, seen or touched before. They may also learn about how this instrument is made and why it is valued. A movement has arisen within social anthropology which aims to attend more adequately to material artefacts. The movement is sometimes referred to as the ontological movement, for reasons that we need not go into. The purpose of this paper is not to examine the positive proposals of this movement, proposals which specify how anthropologists can attend more adequately to artefacts (see Palacek and Risjord 2013; Sivado 2015). Rather it is to examine an argument according to which a certain philosophical doctrine, which anthropologists often commit themselves to when talking about meaning, leads to a less than satisfactory way of attending to artefacts.

The argument is made in the Introduction to Thinking Through Things, a book which is a key text for understanding the ontological movement. The authors of the Introduction are Amiria Henare, Martin Holbraad and Sari Wastell. According to their argument, anthropologists rely on an understanding of what meanings are that commits them to Cartesian dualism (2007: 9). The term 'Cartesian dualism' is used here to refer to the doctrine that the world is divided into two realms: the material realm consisting of matter and, independent from it, the mental realm consisting of minds. (A more precise statement of Cartesian dualism will be given later.) It is said that Cartesian dualism requires that we divide the sciences in a way that reflects this division in the world. On the one hand, there are the natural sciences, which study the realm of matter, and on the other hand, the social and psychological sciences, which study the immaterial realm of minds. But then there is nothing for social anthropologists to say about the material artefacts that they encounter except that these bits of matter are represented in a certain way by some minds, or so the argument maintains (2007: 9). For example, an anthropologist might tell us that a certain musical instrument is represented by people they have studied as a means to win the favour of the gods. The study of material artefacts within anthropology is restricted to the study of how these artefacts are represented by minds.

This argument is intriguing, but I find myself unable to endorse it. To explain my disagreements, it will be useful to identify the premises of the argument. As I shall reconstruct it, the argument has five premises, with 'anthropology' throughout referring to social anthropology:

(1) Many anthropologists understand what meanings are in a way that commits them to the doctrine of Cartesian dualism.

(2) From Cartesian dualism, it follows that we should divide the sciences into the sciences of matter and the sciences of non-material minds.

(3) Anthropology is a science but not a science of matter.

(4) If anthropology is a science of non-material minds, then all that it should say about material artefacts is that they are bits of matter which are represented by some minds in certain ways, specifying those ways.

(5) If anthropology only says about material artefacts that they are bits of matter which are represented by some minds in certain ways, specifying those ways, anthropology is not adequately attending to material artefacts.

From these premises, a conclusion is said to follow: many anthropologists understand what meanings are in a way that commits them to a doctrine that does not allow anthropology to 
adequately attend to material artefacts. I cannot see any problem with the reasoning from the premises to this conclusion. But I shall make objections to premises (1), (2) and (5). In the course of discussing these premises, textual evidence will be provided for attributing the argument above to the authors of the Introduction.

\section{Premise (1)}

Premise (1) of the argument is that many anthropologists understand what meanings are in a way that commits them to the doctrine of Cartesian dualism. One of the sections of the Introduction to Thinking Through Things opens with the following claim:

It remains a commonplace within anthropology and related disciplines that meanings can only be thought of as abstractions - ideas that somehow circulate in the ether, over a material substrate primordially devoid of significance. (2007: 3)

The authors of the Introduction go on to associate the commonplace way of thinking about meaning within anthropology with Cartesian dualism. They quote an anthropologist who tells us that our thinking is still shaped by the Cartesian division of substances into unextended minds and unthinking extended matter (2007: 9). Soon afterwards they write:

...in our Cartesian-Kantian bind, we assume that the manifold of the universe cannot but consist at most of mind and matter (representation or reality, culture or nature, meaning or thing)... (2007:9)

The assumption identified in this claim is supposed to be common to much anthropological work.

From the textual evidence above, we can extract a more precise characterization of Cartesian dualism. As the term 'Cartesian dualism' will be used in this paper, it refers to a doctrine according to which: (i) there are material substances and their properties; (ii) there are minds and their properties; (iii) this is all that there is; (iv) minds are substances that are entirely separate from matter - they are not matter nor are they composed even partly of matter - and material substances are in turn entirely separate from minds. The word 'substance' is being used here in a specialist sense, derived from the writings of Descartes, to mean an entity that can exist independently of other entities. Here, we do not need to investigate further the definition of substance.

The authors of the Introduction do not provide any evidence of anthropologists committing themselves to this doctrine. They quote an author who sounds as if he might agree but this author also does not provide the missing evidence (see Ingold 2000: 340). Few anthropologists would want to commit themselves to such a controversial metaphysical doctrine as Cartesian dualism, at least in their anthropological works, so it is necessary to provide evidence that anthropologists are nevertheless committing themselves to it. At present, premise (1) is inadequately supported.

Furthermore, it is doubtful that it can be supported. To justify this doubt, I will focus on what anthropologists say about word meaning, that is to say, the meanings of individual words. Though there are other kinds of meaning, word meaning is a central case of the kind of meaning which the authors of the Introduction are interested in.

If one examines anthropological works, it is doubtful that one can find many explicit statements along the following lines: "The meaning of a word is a concept. Concepts are the constituents of mental representations, the building blocks from which they are formed. A mental representation is a representation within a mind of how the world is. There are material entities 
but a mind is a non-material entity." If there were many explicit statements along these lines, then there would be good evidence for premise (1), but I have never encountered such a statement in an anthropological work. The vast majority of anthropological works do not explicitly offer a theory of what word meanings in general are, nor do they need to.

Perhaps it will be said that, even if the vast majority of anthropological works do not explicitly offer a Cartesian theory of meaning, many anthropological works do tell us about certain word meanings and, in the process of doing so, they implicitly commit themselves to Cartesian dualism.

It is nothing unusual for an anthropological work to explain the meaning of a given word, used by those studied. But are anthropologists committing themselves to Cartesian dualism when they provide such explanations or make points related to those explanations? Let us take an example of an actual meaning claim to investigate this question. Here is how Evans-Pritchard initially explains the meaning of the Azande word 'mangu':

Mangu, witchcraft, was one of the first words I heard in Zandeland, and I heard it uttered day by daw throughout the months. Azande believe that witchcraft is a substance in the bodies of witches, a belief which is found among many peoples in Central and Western Africa. (1976: 1)

In this passage, the word 'mangu' is explained as meaning witchcraft and we are introduced to a belief about exactly what witchcraft is. Where though is the commitment to Cartesian dualism? So far there does not appear to be any trace of this commitment.

For anyone who recalls the Introduction to Thinking Through Things, the following impression is near unavoidable: the authors of the Introduction would say that Evans-Pritchard commits himself to Cartesian dualism in his talk of what is believed. Here is what I imagine the authors saying. "According to Evans-Pritchard, Azande have beliefs about witchcraft. What EvansPritchard is doing, when talking about what is believed, is implying that the meaning of the word 'mangu' is a concept that is involved in Azande mental representations. Within the minds of the Azande, reality is represented as containing mangu. When an anthropologist explains the meaning of a 'native' term, they usually imply that the meaning is a concept which is involved in the mental representations of those studied. In implying this, they commit themselves to Cartesian dualism."

Even if we concede that many anthropologists do tend to explain word meanings in a way that implies this, we cannot conclude that these anthropologists are thereby committing themselves to Cartesian dualism. To reach this conclusion, we need the following assumption: anthropologists have to be Cartesian dualists to allow for word meanings to be concepts that are involved in mental representations. This assumption is not something we can grant. One reason why is because there are non-Cartesian theories of mental representation (Fodor 1981: 123; Sperber 1996: 26). The most obvious non-Cartesian theory for members of Western culture is as follows: a person's mind is their brain and the brain is something purely material; so when a person mentally represents that the world is a certain way, this is something that happens within their brain. Anthropologists may vary in their attitudes towards this theory, some accepting it, others not. Whatever their personal stances, the crucial point for us is that the meaning explanations in anthropological writings do not appear to clash with this theory, in which case why say they involve a commitment to Cartesian dualism?

In summary, if we look for explicit claims about what meanings are within anthropological works, there is no clear evidence that many anthropologists are committed to a theory of what meanings are which involves a commitment to Cartesian dualism. For there is little or no explicit support for a Cartesian theory of meaning. If, in search of implicit support, we examine the meaning claims that are commonplace within anthropological works - explanations of the 
meaning of this or that word - there is no way to extract a Cartesian account of meaning without relying on a highly controversial assumption. Not only do the authors of the Introduction provide no evidence in favour of premise (1); it is doubtful that there is adequate evidence.

\section{Premise (2)}

Premise (2) of the argument is that from Cartesian dualism, it follows that the sciences should be divided into the sciences of matter and the sciences of non-material minds. In other words, for a Cartesian dualist, a science should either be a science of matter or else a science of mind. There should be no science which is both and no science which is neither. I regard the authors of the Introduction as committing themselves to this premise when they write:

If we are all living in the same world-one best described and apprehended by [natural] science - then the task left to social scientists is to elucidate the... different accounts of that one world. This just follows from the way the dualism of mind and matter apportions questions of difference and similarity... After all, while matter (nature) just is what it is indifferently, mind (culture) can represent it in different ways. So, to the extent that anthropology takes difference as its object, leaving the study of the indifferences of nature to natural scientists, it cannot but be a study of the different ways the world (the one world of Nature) is represented by different people - and particularly by different groups of people. (2007: 9)

According to this passage, if Cartesian dualism is true, then the natural sciences study the world of matter, so the only task left for the social sciences is to study the world of minds, specifically the way that groups of minds represent the world of matter. There are a number of questions that this passage gives rise to, and it seems to me that there are a few confusions as well. But what comes through is that there is no consistent way to be a Cartesian dualist without saying that the sciences should be divided into the sciences of matter and the sciences of non-material minds. The natural sciences would cover the former category, while the latter category is covered by the social sciences (or the social and psychological sciences).

To dispute premise (2), I will consider two possible inquiries which do not fall exclusively into a science of matter or exclusively into a science of mind but can be legitimately pursued even if Cartesian dualism is true. The first inquiry is an inquiry into what there is. Let us imagine that a person pursuing this inquiry concludes that there are material entities and their properties, there are minds and their properties and there is nothing more. Such an inquiry cannot be categorized as belonging exclusively to a science of matter, since it concludes that there are minds and their properties, but nor can it be categorized as belonging exclusively to some science of mind, since it concludes that there is matter and its properties.

The second inquiry is an inquiry into the following questions. Does the body appear to affect the mind? If so, in what ways? Does the body actually affect the mind? If so, in what ways? Such an inquiry also cannot be categorized as belonging exclusively to some science of matter or else exclusively to some science of mind, because the third and fourth questions concern both mind and matter.

The authors of the Introduction define science as the search for representations that transparently and faithfully reflect reality (2007: 11). Now some people would probably dispute whether the first inquiry counts as science, given its conclusions, but a Cartesian dualist who works with this definition of science would have to count both inquiries as science. Yet these inquiries do not fit into a scheme which divides the sciences into the sciences of matter and mind, such that all legitimate scientific inquiry belongs to either to one kind of science or else to the other. In which case, it does not seem that Cartesian dualism requires this division. Since 
both inquiries are legitimate from the point of view of Cartesian dualism, this doctrine allows for scientific work that concerns itself with both mind and matter.

Neither of my example inquiries is anthropology, but a Cartesian dualist can also allow for anthropological research whose objects of interest include both mind and matter. Consider anthropological research into a newly discovered tribe. Such research may take interest in how tribe members intentionally represent the world. But it may also involve studying how the tribe go about satisfying their needs for food and shelter. This will involve a study of their actions within the material world.

If one is a Cartesian dualist, there is something aesthetically satisfying about dividing the sciences into the sciences of mind and the sciences of matter. According to this doctrine, there is a fundamental division in the world between mind and matter; and the sciences are then divided in a way that neatly parallels this fundamental division. But I cannot see how it logically follows from the doctrine of Cartesian dualism that the sciences should be divided in this way; how it logically follows that there should be no science which seeks to acquire knowledge of both mind and matter. There is no logical connection from Cartesian dualism to this conclusion. There is only an aesthetically satisfying connection.

\section{Premise (5)}

Premise (5) is the premise that if anthropology only says about material artefacts that they are bits of matter which are represented by some minds in certain ways, specifying those ways, anthropology is not adequately attending to material artefacts. An example of this way of attending to material artefacts was provided earlier on. An anthropological work might tell us that a certain flute is represented by those who use it as a means to win the favour of the Gods.

The authors of the Introduction are dissatisfied with this representational approach to material artefacts because it gives rise to the question of which representations are correct and they think that we have no choice but to say that ones from our scientific culture are correct, which means not taking concepts from other cultures seriously (2007: 11-12). They are committed to premise (5) because the whole point of their project is to pursue a more satisfactory way of responding to material artefacts within anthropological research. My objection here is not to this premise, taken in isolation, rather to this premise as part of the argument we have been considering.

The authors of the Introduction do not address the philosophical question of whether Cartesian dualism is true. They do not try to contribute to philosophy by determining the answer to this question, rather they are anthropologists seeking a better way of engaging with cultural artefacts. However, given that they portray Cartesian dualism as determining what anthropology should and should not be doing, there is no way for them to defend their project without taking up this philosophical question and arguing against Cartesian dualism. For Cartesian dualism, as they portray it, entails that the proper focus of anthropologists in relation to material artefacts is on how these artefacts are represented.

The previous section disputed whether there really is this entailment, but supposing that there is this entailment is part of the argument as a whole. Consequently, one cannot endorse (5) along with the other premises of the argument without being prepared to do something which the authors of the Introduction are not prepared to do: without inquiring into whether or not Cartesian dualism is true. The strategy of saying, "We are just arguing that another approach is better for the purposes of doing anthropology, and leaving aside whether or not Cartesian dualism is true," cannot work, because Cartesian dualism as they portray it rules out this other 
approach as legitimate anthropology. Cartesian dualism as they portray it is not just a philosophical doctrine about what there is, but also a doctrine that makes demands of anthropologists, and so must be rejected as false in order to claim that there is a better way for anthropologists to engage with artefacts.

In summary, my objection to premise (5) is as follows. It is only possible to endorse this premise along with the other premises of the argument by refuting Cartesian dualism, because according to those other premises Cartesian dualism entails that anthropologists should focus purely on how material artefacts are represented. But the authors of the Introduction to Thinking Through Things, who made the argument to begin with, do not provide us with a refutation.

\section{References}

Evans-Pritchard, E.E. (abridged by E. Gillies). 1976. Witchcraft, Oracles and Magic among the Azande. Oxford: Clarendon Press.

Fodor, J. 1981. The Mind-Body Problem. Scientific American 244 (1): 114-123.

Henare, A., Holbraad, M. and Wastell, S. 2007. Introduction. In A. Henare, M. Holbraad and S.Wastell (eds.), Thinking Through Things. London: Routledge.

Ingold, T. 2000. The perception of the environment: essays in livelihood, dwelling and skill. London: Routledge.

Palacek, M. and Risjord, M. 2013. "Relativism and the Ontological Turn within Anthropology." Philosophy of the Social Sciences 43: 3-23.

Sivado, A. 2015. "The Shape of Thing to Come? Reflections on the Ontological Turn in Anthropology." Philosophy of the Social Sciences 45: 83-99.

Sperber, D. 1996. Explaining Culture: A Naturalistic Approach. Oxford: Blackwell. 